\title{
Mujeres, sociedad y arte. Proyecto colaborativo
}

Women, society and arts. Collaborative project

\author{
Carmen Franco-Vázquez ${ }^{1}$ \\ carmen.franco@usc.es \\ Universidad de Santiago de Compostela, España
}

\section{Resumen:}

Este trabajo narra la realización de un libro colectivo sobre perspectiva de género. En el mundo actual, la imagen de la mujer en los medios resulta muy manipula$\mathrm{da}$, contribuyendo a difundir una imagen interesada y falsa de la mujer. Los futuros maestros deben ser sensibles a esta situación para que no se conviertan en consumidores pasivos. Con el proyecto se les dotó de mecanismos de crítica para contrarrestar una situación inadmisible en el S. XXI. Queremos conseguir que los alumnos reflexionen críticamente sobre el papel de la mujer en la sociedad mediante la acción colaborativa descrita en el texto. La capacidad del Arte para generar imágenes que provoquen emociones nos permite alcanzar nuestros objetivos.

\section{Palabras clave:}

Arte y género; educación artística; trabajo por proyectos; mujer y publicidad.

\begin{abstract}
:
This paper reports the production of a group book about gender perspectives. Nowadays, the image of women in massmedia tends to be manipulated and this contributes to the dissemination of a misleading and false image of women's identity. Future teachers should be especially conscious of this situation so that they do not become passive consumers of publicity. This project aims to offer students mechanisms for criticism and reflection to counteract a situation which in the $21^{\text {st }}$ century should be simply unacceptable. Our goal is that our students reflect criticaIly about the role of women in society by means of a collaborative action which this article explains in detail. The capacity of Art to provide images that elicit emotions allows us to reach our aims.
\end{abstract}

\section{Key words:}

Art and gender; Arts education; projects; women and publicity.

\section{Dirección para correspondencia (correspondence address):}

Carmen Franco Vázquez. Universidade de Santiago de Compostela. Departamento de Didácticas Aplicadas. Facultade de Ciencias da Educación (Campus Norte). Avda. Xoan XXIII s/n. 15782 Santiago de Compostela (España). 


\section{Resumé:}

Ce travail raconte la réalisation d'un livre collectif sur la perspective de genre. Dans le monde actuel, l'image de la femme dans les medias est très manipulée, ce qui contribue à diffuser une image intéressée et fausse de la femme. Les futurs professeurs doivent être spécialement sensibles à cette situation, en en prenant conscience, afin qu'ils ne deviennent pas des consommateurs passifs de la publicité. Avec le projet, on a donné aux élèves des mécanismes de critique pour contrer une situation inadmissible au XXI siècle. Nous voulons parvenir à ce que les futurs professeurs réfléchissent de manière critique sur le rôle de la femme dans la société par une action collaborative, décrite dans le texte. La capacité de l'Art pour générer des images qui provoquent des émotions nous permet d'atteindre nos objectifs.

\section{Mots clés:}

Art et genre; éducation artistique; travail par projets; femme et publicité.

Fecha de recepción: 02-07-2016

Fecha de aceptación: 09-02-2017

\section{Introducción}

Una parte relevante de la enseñanza artística tradicional se fundamenta en prácticas rutinarias muy arraigadas, poco significativas y alejadas de la realidad social que les toca vivir a los niños. Hace ya tiempo que en distintos foros de estudiosos de la educación artística se escuchan voces que animan a comprometerse con unas prácticas de arte que promuevan una mayor presencia de los aspectos sociales en la educación. Creemos que la educación artística es, o puede ser, una práctica social y crítica y está en nuestras manos aprovechar el potencial que tiene el arte para explorar temas de igualdad, de identidad, de perspectiva de género, etc. y "favorecer el desarrollo de un pensamiento crítico" en nuestro alumnado (Adams, 2014, p. 288).

Mujeres y Sociedad fue un proyecto que se desarrolló en el curso 2013-2014 en la materia Educación Visual y Plástica II: Procesos y Proyectos Artísticos de tercer curso de la titulación de Grado de Maestro de Educación Primaria, de la Facultad de Ciencias de la Educación de la Universidad de Santiago de Compostela. El grupo estaba formado por 70 alumnos distribuidos en un grupo teórico y tres prácticos. Las mujeres representaban el $75 \%$ del alumnado.

Partiendo de esta actividad, el presente trabajo pretende avanzar, en la medida de lo posible, en la sensibilización de un colectivo — los maestros en formación - con posibilidades reales de cambiar, a corto 
o medio plazo, la percepción que todavía tienen sobre las mujeres algunos sectores de la sociedad del siglo XXI. Como señalan Subirats y Brullet (2002, p. 148), "el género fue ya parcialmente adquirido al entrar en la escuela, pero la relación escolar puede reforzar su construcción, modificarla o incluso colaborar en su deconstrucción". Sirviéndonos de este pensamiento, creemos que experiencias docentes como la que expondremos a continuación contribuyen, siquiera sea modestamente, al logro de dicho fin.

Antes de entrar en detalle, consideramos oportuno exponer nuestro planteamiento inicial. Y quizás la mejor manera de hacerlo es comenzar con la siguiente pregunta clave:

¿Por qué es importante trabajar con nuestros alumnos, futuros maestros de primaria, las cuestiones de género?

Con sensibilidad hacia el tema, la respuesta es sencilla:

Porque son ellos los que tendrán oportunidades de organizar actividades para conseguir una mayor comprensión hacia la temática de la igualdad de género en el contexto educativo y para fomentar la adquisición de valores tendentes a lograr un reparto de roles más justo y una ciudadanía más igualitaria.

Si tuviéramos que sintetizar nuestros objetivos en breves ítems, podríamos hacerlo afirmando que PRETENDEMOS:

$-1^{\circ}$ Hacer visible lo vulnerables que somos frente a la publicidad.

$-2^{\circ}$ Reflexionar sobre lo que las artes pueden aportar a la educación.

$-3^{\circ}$ Hacer una obra colectiva y colaborativa a través de las aportaciones de estudiantes y artistas.

$-4^{\circ}$ Sensibilizar a un grupo de estudiantes (maestros en formación) con posibilidad de influir sobre la educación de varias generaciones de niños sobre cuestiones de género.

Para conseguir estos objetivos consideramos imprescindible realizar, en primer lugar, algunos apuntes sobre la cuestión de género, tratando, aunque sea someramente, los temas que están implicados en ella a nivel de imagen: el mundo de la publicidad, la educación artística feminista y el papel de las mujeres artistas. Después, partiendo del referente artístico de Linda Ellia, a quien se dedica un epígrafe, se articula una propuesta para hacer una obra colectiva y colaborativa, descrita con amplitud en el epígrafe 4. 


\section{Algunos apuntes sobre publicidad, género y arte feminista}

En una sociedad en la que la publicidad, al servicio de intereses capitalistas y de mercado, tiene tanta fuerza y está tan presente, debemos formar a los futuros profesores dotándolos de estrategias que les permitan educar a los niños para que sean consumidores libres y tengan recursos suficientes con los que afrontar el bombardeo mediático, especialmente pernicioso en todo lo referente a la mujer.

En efecto, en la publicidad, todo lo relacionado con el mundo femenino insiste siempre en un modelo determinado, con frecuencia alejado de toda racionalidad, como se verá.

Así, señala $M^{a}$ Isabel Menéndez (2006):

La belleza, la forma de vestir o los atributos físicos de las mujeres parecen ser lo único importante, radicalizándose esta exigencia en los nuevos programas de la televisión. Las protagonistas de estos espacios, mucho más que las que aparecen en la prensa de información general, son ridiculizadas y acusadas si su imagen no responde a los estereotipos actuales de belleza, convirtiéndose en una nueva forma de descalificación en virtud de la apariencia externa, sin valorar jamás las cualidades intelectuales o académicas (p. 128).

Siguiendo el pensamiento de esta autora, la sociedad actual termina culpabilizando a las mujeres por considerarlas débiles al "ser incapaces de conseguir la belleza"; se llega a acusarlas de falta de control de sus actos y de sus emociones. Y las mujeres, enfrentadas a un discurso que se repite de forma continuada en la TV, la publicidad y los medios de comunicación, terminan sintiéndose culpables, lo que resulta especialmente cruel porque algunas incluso tienen problemas económicos y, por tanto, no pueden pagar cosméticos caros, gimnasios u operaciones estéticas (Menéndez, 2006, p. 54).

Por su parte, Campos Pardillos (1995) es más contundente:

La publicidad es machista. Si acaso dudáramos de ello, basta con que demos la vuelta a la imagen que se nos ofrece, por moderna que esta sea, $y$ tratar de situar al hombre en los papeles asignados a la mujer, lo cual inmediatamente se nos antojaría anormal (p. 166). 
En definitiva, la publicidad crea falsas necesidades que tienen nefastas consecuencias para la sociedad, especialmente por su influencia en la juventud. La mujer joven no consigue identificarse con esa imagen estandarizada, imposible de alcanzar en la mayoría de las ocasiones, lo que puede abocarla a una baja autoestima. Este tratamiento de la figura femenina que se divulga desde los medios, vinculada en su mayoría al sexo, no es la imagen de una mujer real, común, sino un estereotipo de mujer creado para vender. Lo ha expresado muy bien Menéndez (2006):

A partir de mitos como el príncipe azul o la media naranja, la televisión proporciona una manzana envenenada que se encarna en la tiranía estética y en el valor social de la apariencia, donde la superficialidad y la banalidad han venido a sustituir a otras motivaciones sociales (p.146).

Al hilo de esta afirmación, procede apuntar aquí que una tarea prioritaria que incumbe a los docentes es la de dotar a los niños de estrategias que les permitan, por ejemplo, el desarrollo de los recursos necesarios para afrontar el bombardeo mediático al que están sometidos, bombardeo que resulta especialmente dañino cuando la publicidad utiliza a la mujer. Así, algunos autores han acuñado la expresión "violencia simbólica" para designar aquella conducta en la que a través de las imágenes se reiteran determinados estereotipos con relación al mundo femenino (secretaria, madre-esposa, princesa, muñeca...) (Zafra, 2011, p. 62). El estereotipo de mujer en los medios presenta, pues, una mujer en la que se valora, por encima de todas las características, su cuerpo.

Afortunadamente, una de las corrientes de hoy en día en la Educación Artística es la "Educación Artística Feminista", que comprende estrategias educativas en las que se reivindica el papel de las mujeres artistas, se hacen visibles las discriminaciones sufridas por las mujeres o se denuncian los comportamientos patriarcales y machistas que aún persisten en la actualidad. (Marín Viadel, 2000, p. 158 e ss.).

En el monográfico que la revista de la Universidad de Santiago de Compostela, SEMATA, decidió dedicar a los estudios de género, Miguel Anxo Rodríguez (2008) ha puesto de relieve la tarea fundamental de alguna de estas mujeres, considerando a la artista Cindy Sherman como exponente clave de una tendencia que reivindica el papel de la mujer en la sociedad, cuando, con sus autorretratos fotográficos de los años 
setenta y ochenta, explora e investiga sobre los estereotipos femeninos con su propio cuerpo como terreno de ensayos:

La elaboración era al principio fría y desapasionada, mucho más reflexiva que pulsional: construcción de decorados, atuendo, estudiada pose; puestas en escena que evidenciaban los modos de representación de la mujer elaborados por el ojo masculino a lo largo de los tiempos y sancionados por los medios audiovisuales más recientes (p. 430-431).

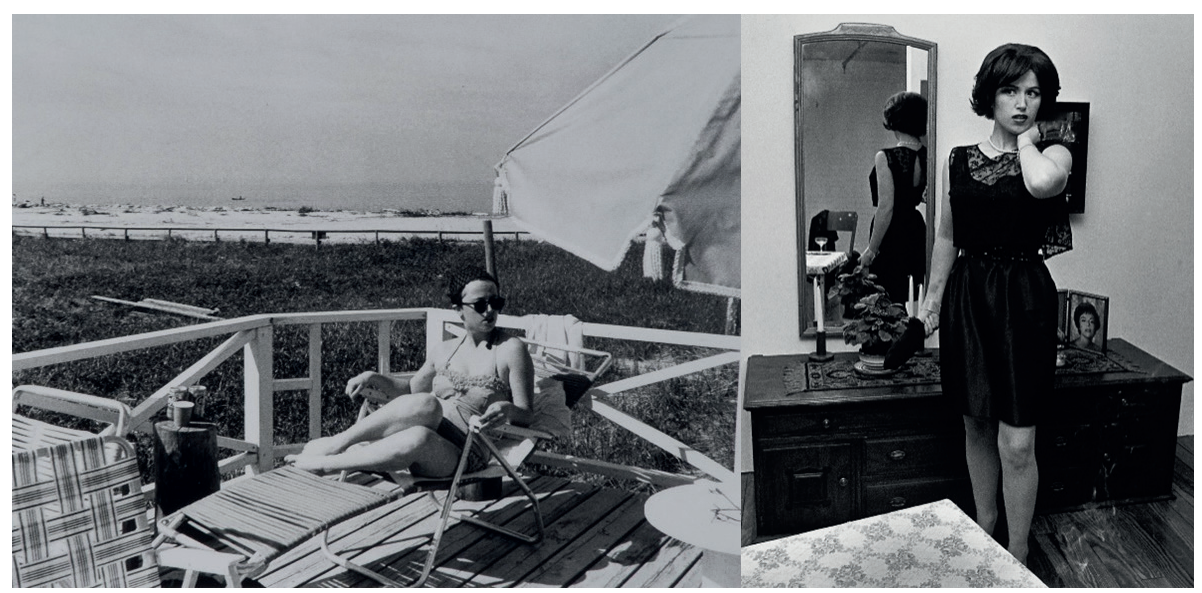

Figura 1. Cindy Sherman. Fotografías de la serie Untitled Film Still \#9 y \#14, 1978. Museo de Arte Contemporáneo de Chicago.

También son destacables los trabajos de arte feminista que aborda la cubana Ana Mendieta. La perspectiva de género en su obra se manifiesta cuando explora la transferencia de elementos identificativos de un género a otro, "plasmando en experimentos y modificaciones faciales que eran filmados en vídeo o fotografiadas: la cara sometida a deformaciones sirviéndose de medias apretadas, un cristal, cabellos mojados sobre el rostro... abordando operaciones simbólicas de "transferencia" de sexo a través de uno de los elementos más claramente identificativos del sexo masculino: las barbas"(p. 438). 


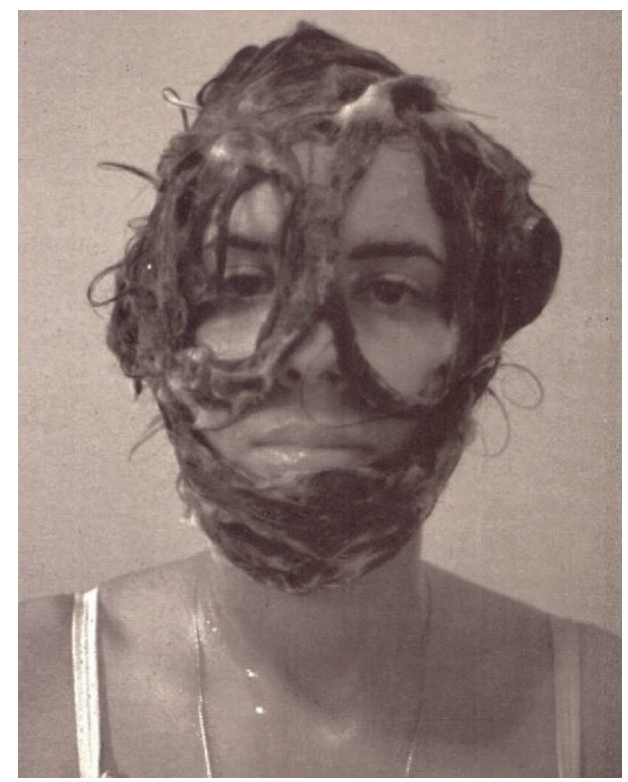

Figura 2. Ana Mendieta. Sin título (Fotografía de la serie Cosmetic Facial Variations), 1972. Galería Lelong.

En los años setenta, la artista Miriam Schapiro quiso recuperar en su obra los materiales y las actividades "propias" de las mujeres, a través de lo que ella denomina "femmages": son collages, ensamblajes, découpages y fotomontajes con los que quiere reivindicar aquellas técnicas que la tradición asimila a las mujeres (la costura, el corte, el patchwork, coser apliques, botones, abalorios, lazos, etc.). Con su obra esta artista quiere dar voz a muchas artistas anónimas, a todas esas mujeres que no han podido alcanzar sus metas por el hecho de ser mujeres y encontrar vedado el camino al gran arte. La explicación de esta realidad nos la aporta Julia Barroso (1995) cuando afirma que:

Nuestro modelo de cultura, como posiblemente el resto de las que conocemos, al tener estructurada una jerarquía interna de carácter patriarcal, postulaba en el fondo que lo masculino era el modelo de lo humano. Por tanto, las condiciones y aportaciones desde el género femenino eran eliminadas de un plumazo desde la supuesta neutralidad de la cultura. Solamente a las mujeres se nos otorgaba el papel reproductor, al que se asociaba mecánicamente el mantenimiento del hogar, y, según culturas, el trabajo agrícola y artesanal no asalariados (p.104). 


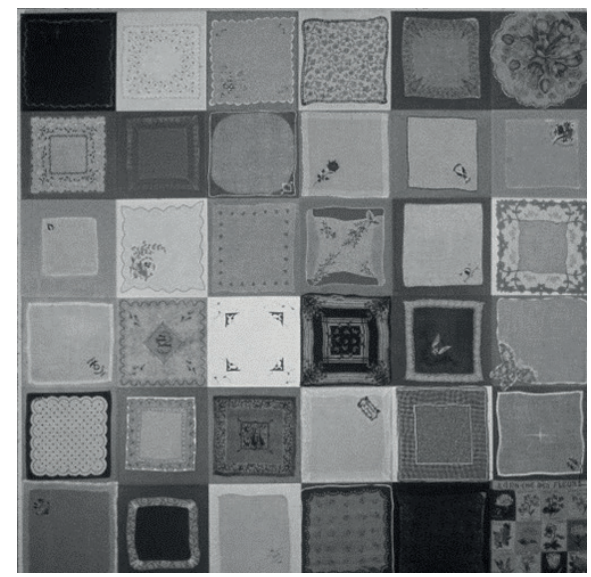

Figura 3. Miriam Schapiro. Connection (Collage textil), 1978. Museo de Arte. Universidad de lowa.

Importa señalar que en la generalidad de los casos se ha minusvalorado el papel de las mujeres artistas, como destaca la autora citada al referirse al desconocimiento que se tiene sobre la obra que realizan, tanto por parte del gran público como por los especialistas formados académicamente, quienes, además, cuando las mencionan utilizan un desafortunado sesgo paternalista: "No importa que la fotógrafa Dora Maar empleara su creatividad y profesionalidad al servicio del gran Guernica de Picasso, pues a ella se la menciona como una de sus muchas y desgraciadas musas" (Barroso, 1995, p. 106). De la misma opinión es Beatriz Porqueres al afirmar que "las biografías que se han hecho de ellas son, profundamente victimistas, tristes, cuando no despreciativas... en ellas se insiste más en los fracasos de sus vidas que en los éxitos... vidas tópicas de mujeres condenadas siempre a perder" (1998, p. 203).

Así pues, no cabe duda de que trabajando la perspectiva de género a través de las artes, estaremos dotando a los estudiantes de estrategias para ser unos consumidores de imágenes críticos, y, por tanto, con más defensas frente a la manipulación de la publicidad. En su ensayo $\mathrm{El}$ arte y la creación de la mente, Elliot Eisner (2002) ya afirmaba la importancia crucial del desarrollo de la imaginación y del refinamiento de la sensibilidad a través del arte:

Invitar a los estudiantes a usarla supone invitarles a ver las cosas de una manera distinta a cómo son. Esto es lo que hacen los científicos y los artistas; 
perciben lo que es, pero imaginan lo que podría ser y luego usan su conocimiento, sus aptitudes técnicas y su sensibilidad para profundizar en lo que han imaginado" (p. 243).

Para la UNESCO, conseguir la igualdad entre los sexos es la tercera meta de los Objetivos de Desarrollo del Milenio y no sólo en aquellos países donde la desigualdad es más palmaria. Las desigualdades entre los sexos siguen estando presentes en muchas sociedades -la nuestra no es una excepción-, ya que a las mujeres se les niega a veces el acceso a la educación (pensemos, por ejemplo, en las niñas de etnia gitana), existen todavía problemas de discriminación en el trabajo y de desigualdad en los salarios, el acceso a puestos de alta responsabilidad sigue teniendo trabas en algunas instancias, etc.

Sin embargo, son muchos los avances que se han conseguido en este terreno. Como dice Michelle Bachelet en la entrevista realizada con motivo de su nombramiento como Directora Ejecutiva de la nueva entidad de las Naciones Unidas para la Igualdad de Género y el Empoderamiento de las Mujeres (ONU Mujeres):

Basta con echar una mirada retrospectiva a los últimos cien años, para percatarse de que los progresos realizados han sido inmensos. Aunque todavía tenemos que afrontar una serie de desafíos, la causa de la igualdad entre los sexos ha cobrado un dinamismo mayor que nunca, tanto en el plano internacional como en la mayoría de los países del mundo... La presencia de mujeres en puestos dirigentes ha hecho comprender a un número cada vez mayor de personas que la mujer debe participar en la vida económica, que es imprescindible poner un término a las violencias ejercidas contra ella y que es preciso recurrir a su capacidad para impulsar cambios que redundarán en beneficio de todos (El correo de la Unesco, 2011, p. 8).

Por último, en el plano legal, cabe recordar que, en nuestro país, la vigente ley de educación (Ley Orgánica de Educación 2/2006, modificada por la LOMCE 8/2013, de 9 de diciembre), en su artículo 1, letra I, señala que el sistema educativo español tiene como uno de sus principios "el desarrollo, en la escuela, de los valores que fomenten la igualdad efectiva entre hombres y mujeres...". A la vista de esta declaración programática, estimular en los futuros docentes la realización de proyectos que contemplen estos principios es una tarea que no debe 
descuidarse. En esta línea, conviene apuntar que con proyectos interdisciplinares como éste se pueden trabajar no sólo cuestiones de género sino también aspectos variados del curriculum de Primaria. Pensando en una posible aplicación del Decreto 105/2014 de 4 de septiembre (vid. anexo I, referente a las disciplinas troncales) de la Comunidad Autónoma Gallega, es evidente que con aquéllos se pueden desarrollar muchas otras cuestiones de forma colaborativa. Así, en lo que atañe a los proyectos relativos a cuestiones sociales y éticas ${ }^{2}$, podrían trabajarse los siguientes: "observación de igualdades y diferencias entre las personas", "los movimientos migratorios, el éxodo rural, la emigración a Europa, la llegada de inmigrantes a nuestro país", "el consumo y la publicidad" y "la influencia de la publicidad en nuestras prácticas diarias" (FrancoVázquez, 2015, p. 31).

\section{Referente artístico: Linda Ellia}

Hemos elegido a esta autora como referente artístico no sólo por el hecho de ser mujer, sino también porque su obra artística Notre combat presentaba unas características especialmente atractivas para nuestra propuesta colaborativa.

Linda Ellia es una artista y pintora afincada en Francia de origen sefardí. Cuando por casualidad llegó a sus manos un ejemplar del libro de Adolf Hitler, Mein Kampf, traducido al francés (Mon Combat), se vio invadida por una corriente de sensaciones y sentimientos muy fuertes. ¡Tanto horror! ¡Tantas muertes! Impactada, no descansó hasta que consiguió conjurar sus miedos y sus iras dibujando sobre las páginas. En un determinado momento imaginó la idea de rehacer el libro, pero no quiso hacerlo sola, y, enviándolas por correo, repartió las páginas entre gente anónima y gente implicada en el Holocausto, gente afectada por otras luchas y por otras dictaduras para, entre todos, reescribir el libro y transformarlo en Notre Combat.

$2 \mathrm{Y}$, en lo referente a proyectos medioambientales, citamos algunos contenidos de las áreas sociales y de la naturaleza: "identificación del ruido como una fuente de contaminación acústica", "identificación de fuentes sonoras del entorno próximo", "intervención humana en el medio próximo, contaminación atmosférica y cambio climático", "desarrollo sostenible y consumo responsable", "uso responsable del agua y valoración del aire limpio para la vida", "desarrollo de actitudes individuales y colectivas frente a determinados problemas medioambientales". 


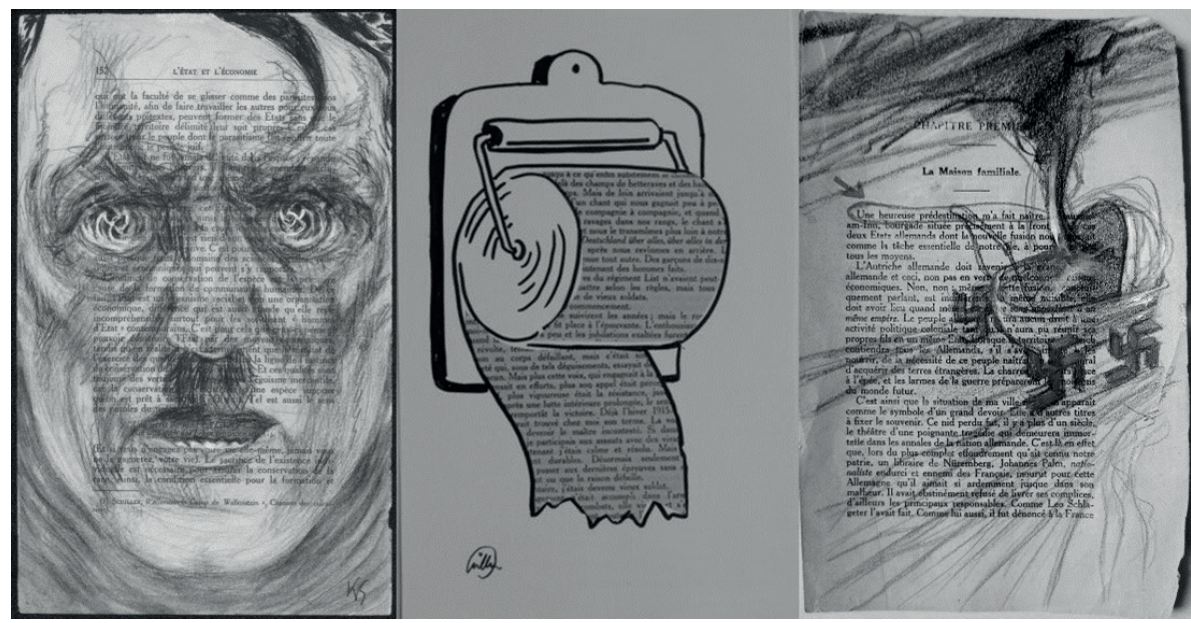

Figura 4. Ejemplos de páginas del libro de Hitler transformadas por gente anónima. (www.notrecombat.net).

Considerando que el arte es una buena manera de comprometerse sin armas ni dolor, quiso que los delirios de un dictador se transformasen en una obra plural, que sirviese de plataforma para mostrar que la lucha contra la tiranía es posible desde la colectividad. Poco a poco fue recibiendo las hojas de nuevo, hasta recuperar más de 500 . El proyecto colaborativo de esta artista terminó con una gran exposición de todas las páginas recogidas; y esta exhibición fue recorriendo, de forma itinerante, varios países: en febrero de 2009 estuvo en el Théâtre Meyrin, de Ginebra (Suiza); en febrero de 2010, en el Contemporary Jewish Museum de San Francisco (USA); en junio de 2011, en el Mémorial de Caen (Francia); y en junio de 2012, en el Museen der stadt nürnberg de Alemania.

Tal y como lo concibió Linda Ellia, su trabajo no se limitó sólo a la memoria del Holocausto, sino que quiso ser un aliento de esperanza para toda forma de racismo, persecución y violencia. Es una obra colectiva y reivindicadora que hace presente las emociones y sentimientos de los artistas, escritores, actores, periodistas, deportados, judíos, palestinos, sirios, tibetanos, kurdos, estudiantes y gente anónima. En palabras de esta artista:

Hoy en día, los agresores no se Ilaman Hitler y las víctimas no son necesariamente Judíos. Quiero que la historia no se repita. Espero con todo mi corazón que la chispa de encendido no muera jamás. Deseo que a través del arte nos comprometamos sin armas y lágrimas (extraído de la entrevista que Frédéric Vignale realizó en el año 2006 para el diario Le Mague). 


\section{Mujeres y sociedad. Libro Colectivo}

En el aula de $3^{\circ}$ curso de Magisterio, la propuesta artística para tratar la perspectiva de género consistió en hacer un libro colectivo. Este proyecto está inspirado en la obra de Linda Ellia anteriormente descrita. Como punto de partida, se necesitaba un libro con una temática que inspirase o provocase respuestas y reflexiones en torno al tratamiento de las mujeres en la sociedad. El libro Rosas y espinas. Álbum de las españolas del siglo XX, de Ángela Carmona, se consideró muy pertinente para elaborar la propuesta, ya que, al tener como eje central distintas cuestiones del universo femenino, proporcionaba una base adecuada para el proyecto que se pretendía llevar a cabo.

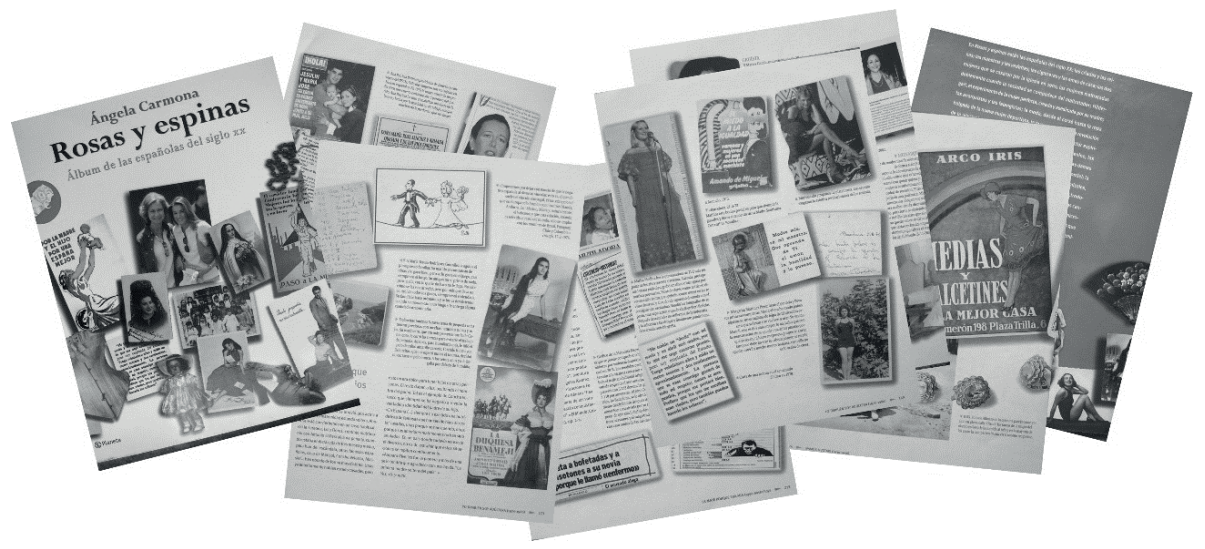

Figura 5. Cubierta y algunas páginas del libro Rosas y espinas. Álbum de las españolas en el siglo XX.

Se trata de un libro muy visual, con un componente gráfico abundante, que va narrando la vida diaria de las mujeres del siglo XX, centrándose en aspectos cotidianos.

Muchas de las historias narradas en sus páginas son sorprendentes y van acompañadas de fotografías, imágenes publicitarias, páginas de periódicos, etiquetas o folletos antiguos. El libro contiene la historia de muchas mujeres anónimas que lucharon por conseguir un trato igualitario y la misma dignidad que tenían los hombres.

Una vez repartidas las páginas del libro al alumnado de magisterio, se les plantearon las siguientes preguntas sobre la hoja del libro que cada uno tenía: 


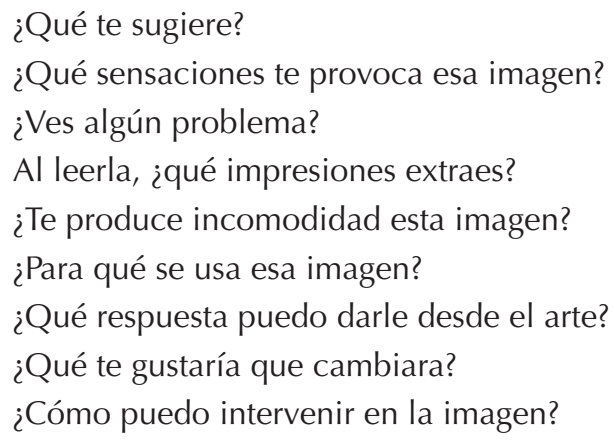

Como paso previo, la obra de Linda Ellia había sido presentada en clase. El procedimiento a seguir era simple y claro: podían hacer su intervención con toda libertad, disponiendo de todos los recursos que el arte pone en sus manos para ello (pintar, dibujar, romper, arrugar, coser, recortar, pegar, escribir, plegar...).

El hecho de partir de unas páginas con imágenes facilitaba la composición a aquellos alumnos menos dotados de aptitudes artísticas, al mismo tiempo que no era un inconveniente para el alumnado con inquietudes y formación plástica más desarrollada.

La elección del libro, en este caso, no tenía unas connotaciones negativas a priori, como en el caso del libro Mein Kampff, pero, al abarcar aspectos relacionados con las mujeres a lo largo de un período de tiempo tan largo, facilitaba la reflexión sobre temáticas muy diversas y suscitaba emociones muy interesantes: el tratamiento de la mujer en la publicidad, la formación de la mujer en otras épocas, el acceso al mercado laboral, la evolución de las relaciones de pareja, etc.

El resto de las hojas que sobraron al finalizar el curso fueron repartidas entre artistas y gente relacionada con el mundo del arte, para que también hiciesen, de forma voluntaria, su contribución a este libro colaborativo.

Una vez que todas las hojas fueron devueltas, las aportaciones fueron expuestas en el aula para compartir y comprender el trabajo como un único objeto. De este modo, se consiguió crear una nueva narrativa a partir de las páginas intervenidas con diferentes actuaciones artísticas de los alumnos, en las que, al añadir sus propias reflexiones, ahondaron en la problemática de la mujer desde una visión del siglo XXI.

El diseño del conjunto final, concebido como un objeto, fue mi aportación a la obra colaborativa. Se trata de un paquete pendiente de ser en- 
viado; es un envoltorio cerrado que está atado con una cuerda, lacrado y sellado, pero la dirección y el nombre del destinatario están en blanco, ya que todos debemos ser los receptores del mensaje que encierra esta obra colectiva.

Terminamos este epígrafe señalando que, aunque a día de hoy se puede afirmar que es mucho lo que se ha avanzado, no podemos dejar de caminar en esta dirección porque tenemos la obligación de conseguir que el enorme esfuerzo realizado por estas mujeres del siglo $\mathrm{XX}$, antepasadas nuestras, haya servido para algo. El futuro que las mujeres se merecen lo demanda.

\section{Valoraciones del alumnado ${ }^{3}$}

En este apartado, como ejemplo de la valoración que la experiencia Mujeres y Sociedad tuvo en el alumnado, extraemos, seguidamente, algunos párrafos de las reflexiones del alumnado. En aras de la espontaneidad, recogemos literalmente sus valoraciones. Asimismo, incluimos algunas imágenes como muestra de la obra plástica de los alumnos:

"La temática realmente me pareció muy buena, ya que casi nunca se propone algo relacionado con la mujer de una forma tan directa y creo que temáticas así se deberían de proponer más a menudo" (Antonio SC).

"Supuso un altavoz para gritar nuestros pensamientos y reivindicar nuestros derechos como mujeres. Resulta un ejercicio enriquecedor poder expresarnos como personas, con derecho a hacer todo aquello que nos propongamos y no quedarnos relegadas a la figura del hombre. Por ello decidí dibujar un corsé en mi página, que tiene representada a una mujer icono sexual. Todos/ as tenemos el deber de desatar este corsé y no ver a la mujer como un ser inferior, un icono sexual o una buena ama de casa" (Iria VO).

3 Los comentarios sobre su implicación provienen del apartado de reflexión y autoevaluación con el que todos los proyectos de aula concluyen. La descripción y análisis de la técnica empleada en las intervenciones se entregaba acompañando a la página del libro. 


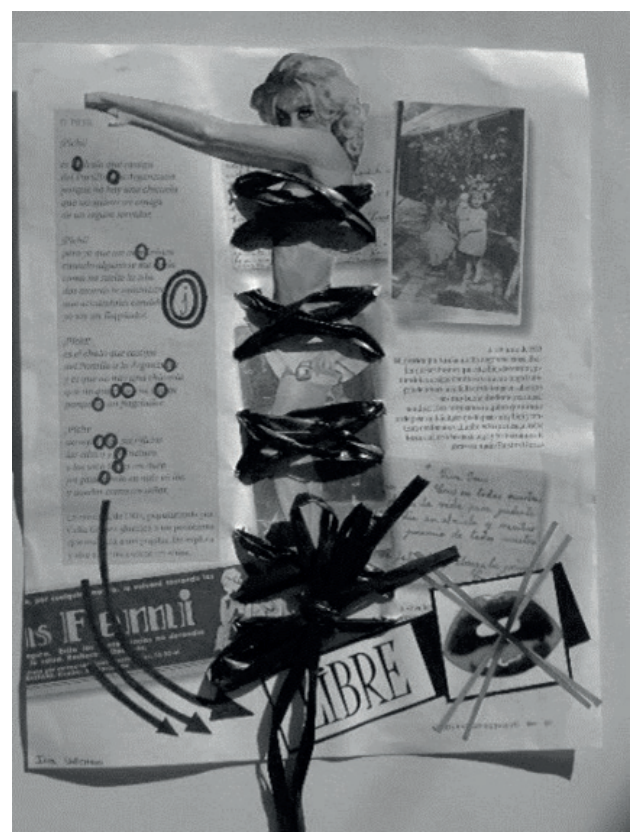

Figura 6. Trabajo de Iria VO para el libro colaborativo.

"El proyecto supuso una gran reflexión interior, una reafirmación de mi forma de pensar, siendo el respeto y la igualdad algo muy importante en mis valores personales" (Lúa VA).

"Creo que ha sido un proyecto muy reivindicativo y social. Además, versa sobre un tema actual y de gran importancia. Me ha gustado mucho la idea del libro colectivo y las explicaciones sobre las mujeres relevantes. Es un proyecto con una gran carga de educación en valores y dotado de gran transversalidad" (Laura SR).

"Me quedaría con una idea principalmente: lucha. Muchas de las mujeres que aparecen en estas noticias son luchadoras natas que vivieron en tiempos difíciles para intentar ponernos las cosas, ahora, un poco más fáciles. Aun así, queda mucho camino por recorrer y un trabajo como éste sirve para recordarnos que, como todo en esta vida, hay que ser constante, si queremos conseguir lo que tanto deseamos. A veces, aunque sea de forma sencilla, con una crítica o un halago a dichas noticias, o con la creación de un libro colectivo, recordamos al mundo que seguimos ahí, luchando por triunfar" (Clara RL). 
"La hoja la corté en diagonal para representar el pensamiento que podía tener una mujer en la época. Una mitad podría ser su propia manera de pensar y la otra mitad la que está influenciada por la Iglesia. Esa segunda mitad está cortada en varios trozos, lo que se puede entender como las diferentes ideas que implantaba la Iglesia en la mente de las mujeres y que había que cumplirlas tal como la Iglesia decía o si no serían castigadas por Dios" (Alba PD).

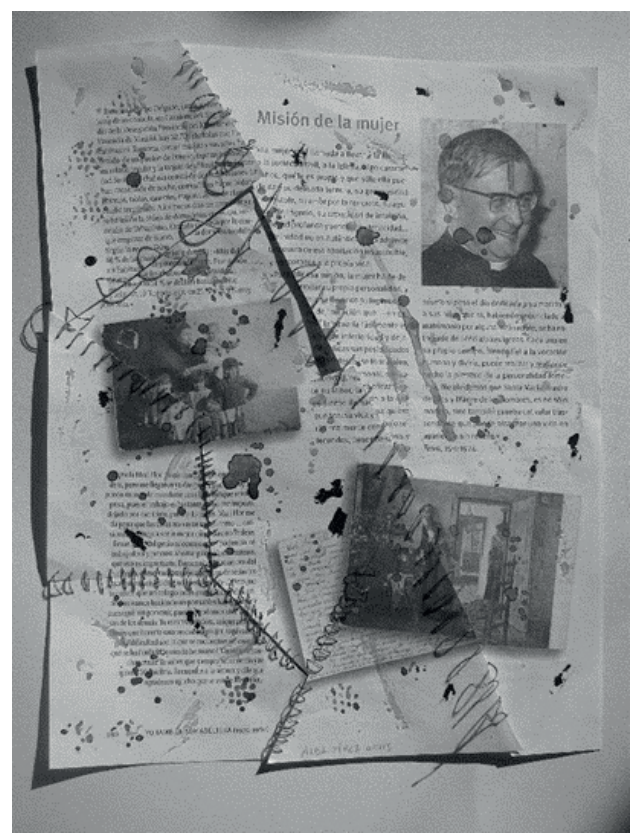

Figura 7. Trabajo de Alba PD para el libro colaborativo.

"En mi lámina cubrí la mitad del rostro de las mujeres y dibujé las lágrimas rojas. Además de esto, incluí la imagen de una silueta de mujer que está siendo maltratada por un hombre. En ésta, las lágrimas rojas representan a la sangre real. Esta imagen fue puesta para reflexionar sobre este tema en particular que nos encontramos a diario en los medios de comunicación: las muertes provocadas por la violencia de género. Para clamar por un cambio social, dibujé en la parte inferior izquierda de la lámina una X que simboliza el fin que se debe alcanzar cuanto antes para evitar que haya más víctimas. Este cambio, como casi la mayoría, puede empezarse desde la educación en las escuelas, formando futuros ciudadanos y ciudadanas competentes y respetuosos con la sociedad y con el mundo" (Eva OR). 


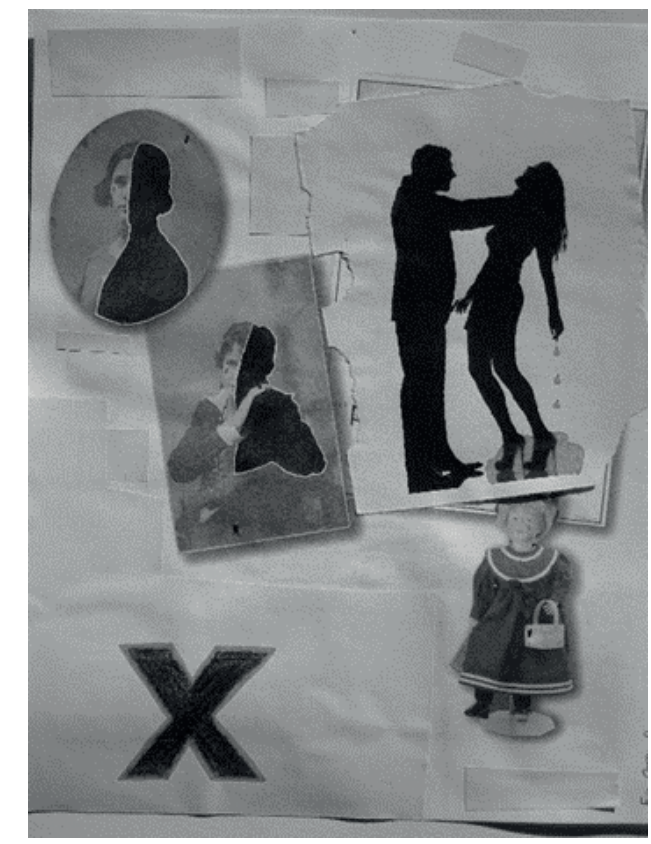

Figura 8. Trabajo de Eva OR para el libro colaborativo.

"Con la modificación que le apliqué a la lámina quise mostrar las diferentes vidas que presentaban las mujeres en la época de la Guerra Civil española. Mientras que unas tenían vidas más fáciles, sin complicaciones, como era el caso de las actrices y cantantes, otras vivían en sus carnes los efectos de la guerra, como el caso de la costurera que se quedó sin su máquina de coser debido a un ataque de los militares. Lo que hice en mi lámina fue representar una especie de edificio en el que se muestran mediante cuatro ventanas las diferentes vidas de mujeres: una costurera, una militante, una actriz y una vedette" (Marta NA).

"Coloqué un lazo rosa para hacer referencia a las mujeres que luchan contra el cáncer, sea de mama, de útero o cualquier otro, porque son personas realmente valientes, son unas supervivientes. Para resaltar esta idea, escribí sobre el lazo unas palabras... Luchadoras. ¿Qué sería de este mundo sin mujeres? Además, con ellas quiero invitar a la reflexión de los espectadores. Para finalizar, quería añadir que quizás me siento arrepentida de haber escogido el rosa como color relacionado con el género femenino, ya que no debería existir un color predeterminado para cada sexo, todos son perfectamente válidos para los dos géneros. De esta manera, me di cuenta de lo profundamente instaurados que están los estereotipos sexistas" (Silvia OM). 


\section{Recapitulación final}

Con este trabajo, Mujeres y Sociedad, se incentiva el empleo de una metodología por proyectos entre el alumnado de magisterio, ya que, al vivir el proyecto como alumnos, perciben las ventajas de este sistema y se incentiva que lo lleven a la práctica en su quehacer como maestros.

Como experiencia educativa en un aula de formación de profesorado, el proyecto Mujeres y Sociedad se puede considerar ampliamente cumplido. El alumnado de magisterio, como se aprecia en sus reflexiones, se enfrentó a problemas de composición de imágenes, a la elaboración de formas nuevas que diesen significado a lo que querían expresar y a la exploración de diferentes técnicas con distintos resultados. Además, al poner en común el trabajo colectivo, todos tuvieron conocimiento de las distintas etapas que las mujeres españolas del siglo XX vivieron. Asimismo, pudieron observar cómo cambiaron muchas actitudes en cuestión de género, y percibieron cómo algunas todavía permanecen.

Teniendo a la vista las manifestaciones de las alumnas, con este proyecto quedó patente la influencia que tiene la publicidad en la consideración de la mujer en la sociedad; afloró en sus conciencias las posibilidades que ofrece el arte para abordar cuestiones de actualidad y hacerlas visibles; constataron la invisibilidad de las mujeres artistas y conocieron en detalle el trabajo de una de ellas; diseñaron proyectos artísticos basados en la perspectiva de género, para llevar a cabo en la enseñanza primaria; $y$, lo más reseñable, sintieron la necesidad de trabajar en las escuelas aspectos relacionados con el arte y las mujeres.

Finalmente, con esta propuesta artística también se favorece la elaboración de proyectos interdisciplinares para llevar a cabo en la escuela primaria. Aunque en éste la temática de partida fue la perspectiva de género y el arte, pueden elaborarse propuestas similares con otros temas, aprovechando el enorme potencial que ofrece la Educación Artística para los proyectos colaborativos. Ésta contribuye al desarrollo cognitivo y emocional de los individuos y sociedades de forma equilibrada. Como se sabe, además de favorecer la adquisición de habilidades para la vida, el pensamiento innovador y creativo, las destrezas interpersonales y la reflexión crítica, la Educación Artística potencia la capacidad de adaptación y la conciencia cultural de los individuos. Se facilita de esta forma la construcción de identidades personales y colectivas, así como el desarrollo de la tolerancia y aceptación hacia los demás. Las actividades 
de estos futuros proyectos deberán ser diseñadas con acciones diversas en las que los niños reflexionen de una manera analítica sobre las cuestiones planteadas, de modo que tengan que trasladar esas ideas a creaciones propias en las que el arte sea el eje en torno al cual se surtan de referentes.

\section{Referencias}

Adams, J. (2014). Critical Discourses around Participation in Arts Education: iJADE 2013. International Journal Of Art \& Design Education, 33(3), 288-290.

Barroso Villar, J. (1995). Aportación femenina de las vanguardias pictóricas vs. Imagen de la mujer en la pintura de vanguardia. En Caramés, J. L. y González, S. (Eds.), Género y sexo en el discurso artístico (pp. 103-113). Oviedo: Servicio de Publicaciones de la Universidad de Oviedo.

Bowman, R. (2011). A Grand Melee of Radical Procedures: Miriam Schapiro on CalArts and the Feminist Art Program. Recuperado de http://www.eastofborneo.org/articles/agrand-melee-of-radical-procedures-miriam-schapiro-on-calarts-and-the-feminist-artprogram

Campos Pardillos, M. Á. (1995). Women's Lib - Women's Ads: la mujer como destinataria del discurso publicitario. En Caramés, J. L. y González, S. (Eds.), Género y sexo en el discurso artístico (pp. 155-167). Oviedo: Servicio de Publicaciones de la Universidad de Oviedo.

Carmona, A. (2004). Rosas y Espinas. Álbum de las españolas del siglo XX. Barcelona: Planeta.

Eisner, E. W. (2002). El arte y la creación de la mente. Barcelona: Paidós.

Ellia, L. (2007). Notre combat. París: Seuil.

España. Decreto 105/2014, de 4 de septiembre, por el que se establece el currículo de la educación primaria en la Comunidad Autónoma de Galicia.

España. Ley Orgánica de Educación 2/2006, modificada por la LOMCE 8/2013, de 9 de diciembre.

Franco-Vázquez, C. (2015). La educación visual y plástica en el nuevo curriculum de educación primaria. IBER, Didáctica de Ciencias Sociales, Geografía e Historia, Barcelona, 79(2), 25-32.

Gallego, J. (2013). De reinas a ciudadanas: Medios de comunicación, ¿motor o rémora para la igualdad? España: Aresta Mujeres.

Lorrie, C. (2014). The power of femmage. Recuperado de http://femmage.blogspot.com. es

Marín Viadel, R. (2000). Didáctica de la Expresión Plástica en Educación Artística. En Rico Romero, L. y Madrid Fernández, D. (Eds.), Fundamentos didácticos de las áreas curriculares (pp.153-207). Madrid: Síntesis.

Menéndez Menéndez, Ma I. (2006). El zapato de Cenicienta. El cuento de hadas del discurso mediático. Oviedo: Trabe. 
Porqueres, B. (1998). Perspectivas históricas de la situación de las artistas. Arte, Individuo y Sociedad, 10, 199-212.

Rodríguez González, M. A. (2008). De mujeres y máscaras. Lo grotesco y la cuestión del género en el arte actual. SEMATA. Ciencias sociales e Humanidades, 20, 425-443.

Sopova, J. (2011). Entrevista de Michelle Bachelet. El correo de la UNESCO, 2(LXIV), 7-8. Recuperado de http://unesdoc.unesco.org/images/0019/001922/192261s.pdf

Subirats, M. y Brullet, C. (2002). Rosa y azul: la transmisión de los géneros en la escuela mixta. En González, LA. y Lomas, C. (Coords.), Mujer y educación. Educar para la igualdad, educar desde la diferencia (pp.133-168). Barcelona: Graó.

UNESCO, Informe de Seguimiento de la EPT (Enseñanza Para Todos) en el Mundo, ENSEÑANZA Y APRENDIZAJE: Lograr la calidad para todos. Resumen sobre género, 2013/14.

Vignale, F. (2015). Linda Ellia fait du livre d'Hitler une Oeuvre artistique collective. Le MAGE. 28 de septiembre de 2006. Recuperado de http://www.lemague.net/dyn/spip. php?article2474

Zafra, R. (2011). Aprender a ser/aprender a ver. Género y mito en la construcción de imágenes visuales. En Marín Viadel, R. Infancia, Mercado y Educación Artística (pp. 62-76). Málaga: Aljibe. 